University of Northern lowa

UNI ScholarWorks

Summer Undergraduate Research Program

2020 Summer Undergraduate Research (SURP)

Jul 31st, 1:00 PM - 3:30 PM

\title{
Chemical substitution induced half-metallicity in $\mathrm{CrMnSb}(1-\mathrm{x}) \mathrm{Px}$
}

\author{
Devon VanBrogen \\ University of Northern lowa \\ Adam Ramker \\ University of Northern lowa
}

See next page for additional authors

Let us know how access to this document benefits you

Copyright (C2020 Devon VanBrogen, Adam Ramker, Evan O’Leary, and Pavel Lukashev

Follow this and additional works at: https://scholarworks.uni.edu/surp

Part of the Physics Commons

\section{Recommended Citation}

VanBrogen, Devon; Ramker, Adam; O'Leary, Evan; and Lukashev, Pavel, "Chemical substitution induced half-metallicity in CrMnSb(1-x)Px" (2020). Summer Undergraduate Research Program (SURP). 2. https://scholarworks.uni.edu/surp/2020/all/2

This Open Access Presentation is brought to you for free and open access by the Student Work at UNI ScholarWorks. It has been accepted for inclusion in Summer Undergraduate Research Program (SURP) by an authorized administrator of UNI ScholarWorks. For more information, please contact scholarworks@uni.edu. 


\section{Author}

Devon VanBrogen, Adam Ramker, Evan O'Leary, and Pavel Lukashev 


\section{Chemical substitution induced half-metallicity in $\mathrm{CrMnSb}_{(1-x)} P_{x}$}

\section{University of iorthern lowa}

Devon VanBrogen,' Adam Ramker,' Evan O'Leary,' Pavel Lukashev'

1 Department of Physics, University of Northern lowa, Cedar Falls, IA 50614
2 U.S. DEPARTMENT OF ENERGY

\section{Background}

$\checkmark$ Research on magnetic materials for potential applications in spin-based electronics: one of the most active fields in academia and industry.

$\checkmark$ High degree of spin polarization - wanted in spintronics.

$\checkmark$ Spintronics - an emerging technology utilizing a spin degree of freedom.

$\checkmark$ Various mechanisms alter degree of spin polarization - mechanical strain, structural disorder, temperature, termination surface/interface in thin film multilayer geometry, etc.

$\checkmark$ Magnetic materials that conduct electrons of only one spin are called half-metals, and have a great potential in spintronic devices.

\section{Motivation and Methods}

$>\mathrm{CrMnSb}$ and similar half-Heusler alloys may crystallize in two different phases: $\alpha$-phase, and $\gamma$-phase.

$>$ The $\gamma$-phase is energetically favorable and is nearly half-metallic.

$>$ Can we make it truly half-metallic by external pressure / strain, or by chemical substitution?

$>$ Epitaxial strain is more realistic scenario in thin-film applications.

$\checkmark$ DFT (density functional theory) - Vienna Ab Initio Simulation Package (VASP).

$\checkmark$ Computations performed at the Department of Physics computing facilities (20-node Beowulf cluster), UNI.

\section{CrMnSb: ground state properties}
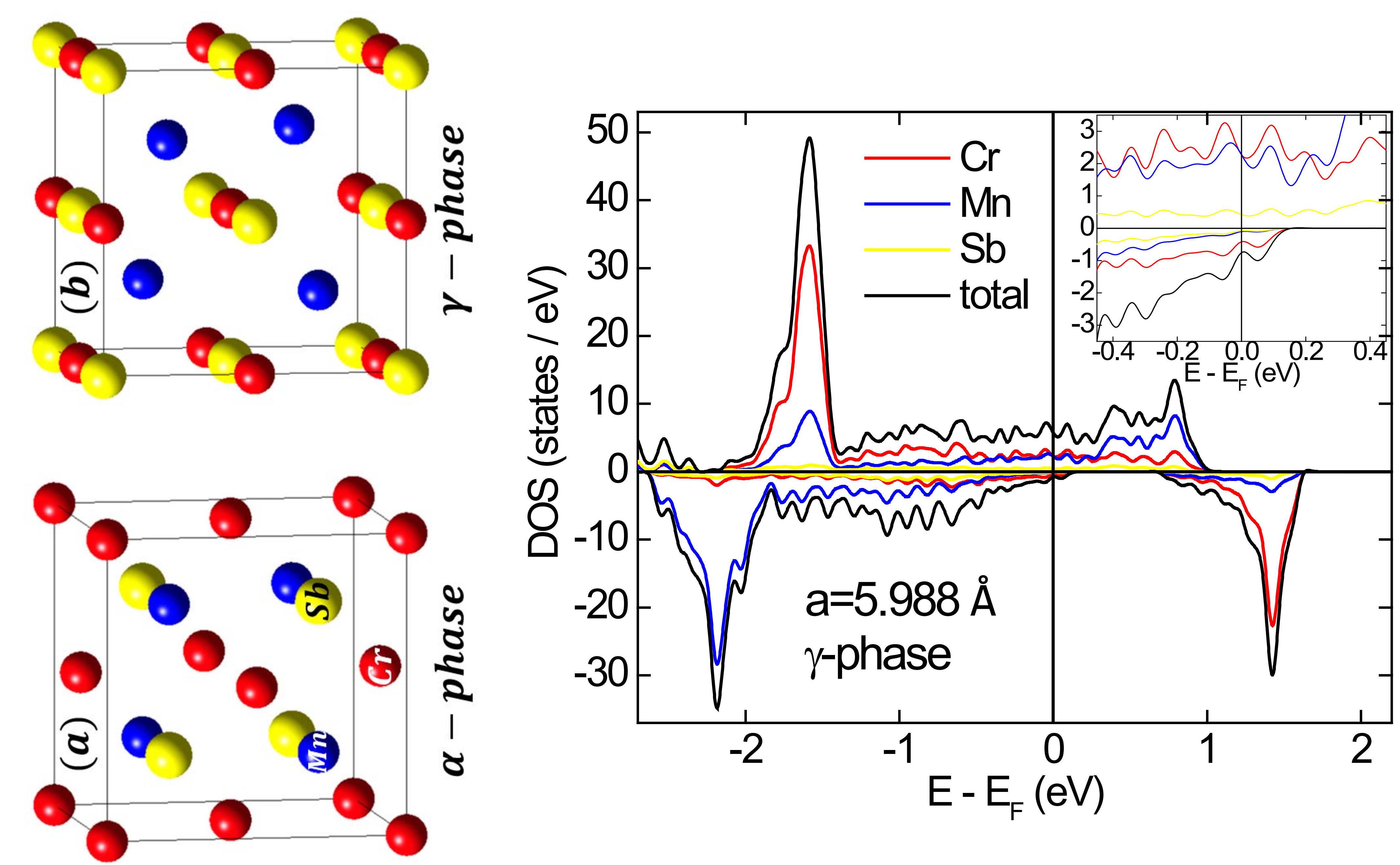

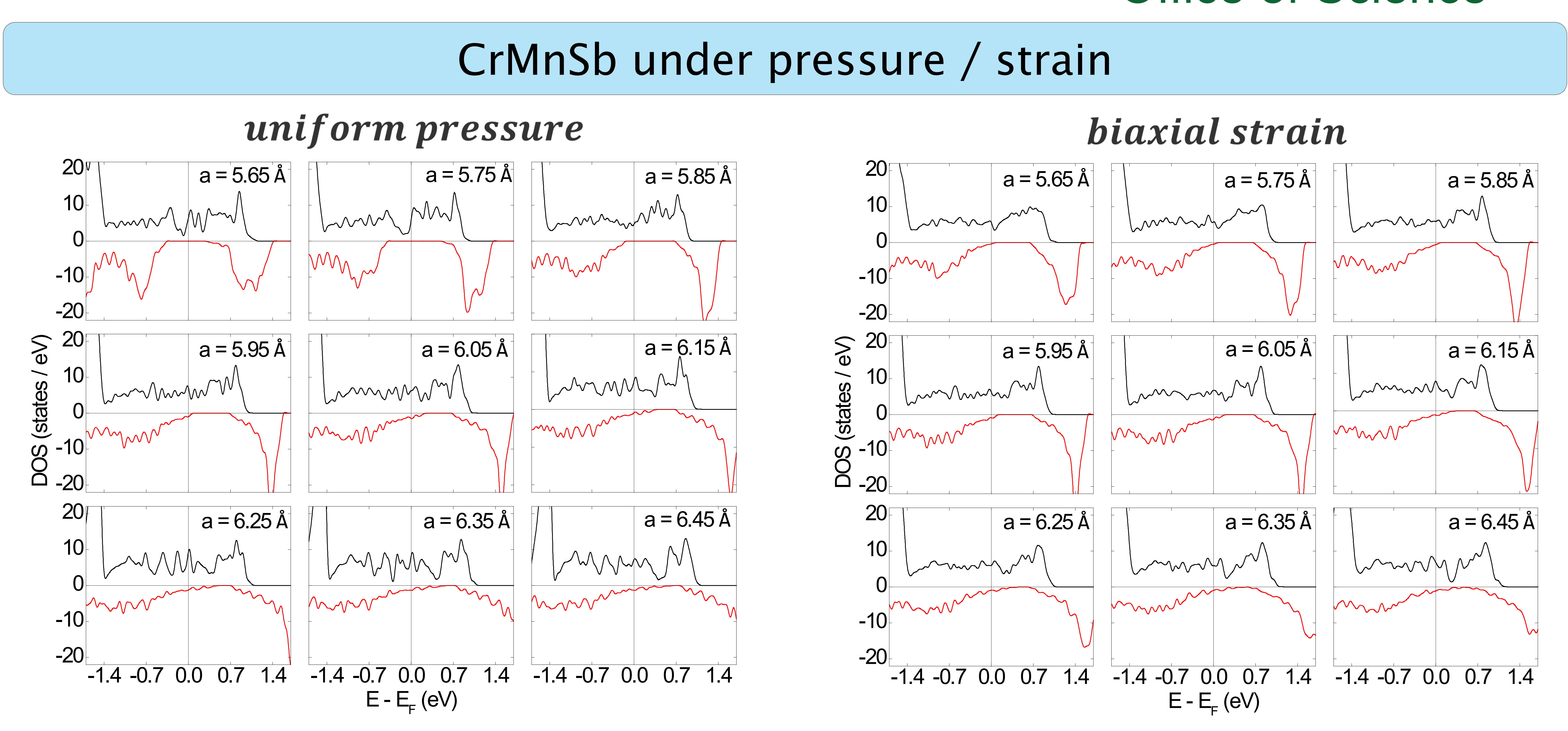

$\mathrm{CrMnSb}_{0.5} \mathrm{P}_{0.5}$ : effect of chemical substitution
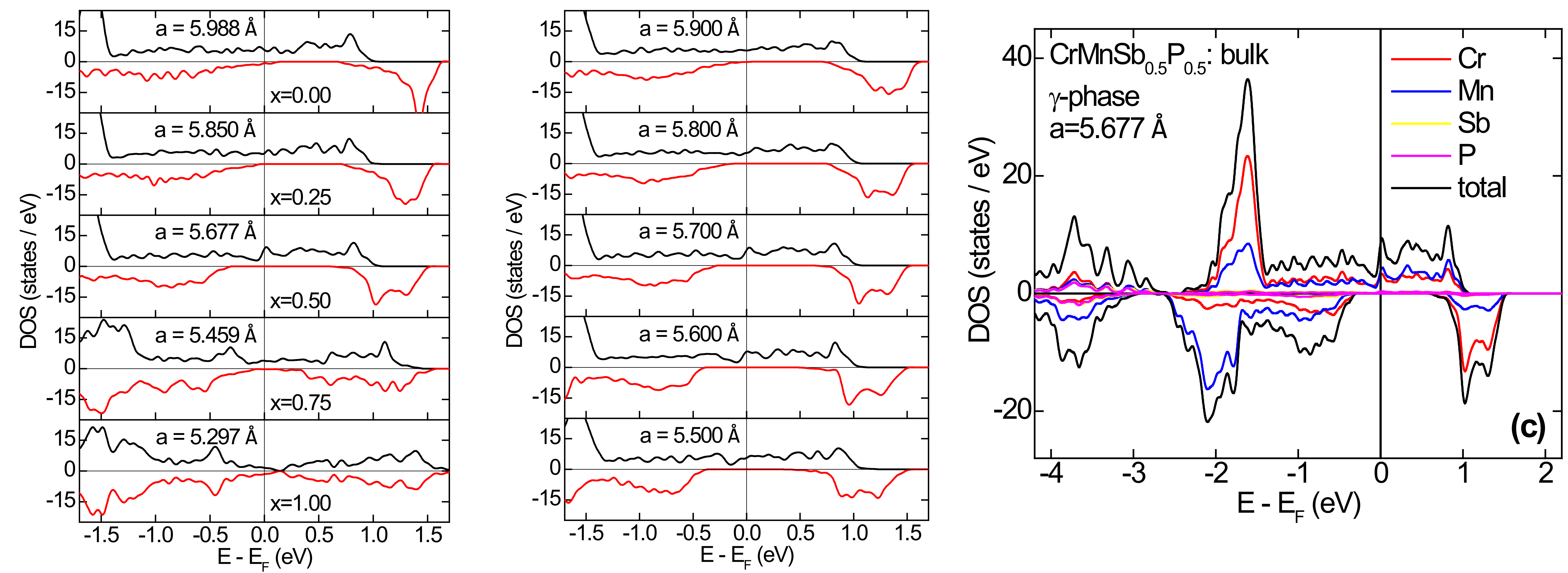

\section{Conclusions and Acknowledgments}

$\checkmark \mathrm{CrMnSb}$ is not half-metallic in ground state, despite earlier reports.

$\checkmark$ Half-metallic transition in $\mathrm{CrMnSb}$ could be induced by a chemical substitution of Sb with $\mathrm{P}$.

$\checkmark$ Sb-to-P substitution results in a volume reduction of the unit cell $\rightarrow$ half-metallic transition.

$\checkmark$ This research was funded by the U.S. Department of Energy, grant number DE-SC0020564. 